\title{
Left Atrial Myxoma in a Woman with Postpartum Heart Failure: The Culprit or an Incidental Bystander
}

\author{
Musa Mohammed Baba1*, Mohammed Abdullahi Talle², Faruk Buba², Kabir M. Fagge \\ ${ }^{1}$ Department of Internal Medicine, Federal Medical Centre Nguru, Nguru, Nigeria \\ ${ }^{2}$ Department of Medicine, College of Medical Sciences, University of Maiduguri, Maiduguri, Nigeria \\ ${ }^{3}$ Ma'aji Amar Muhammad Hospital Limited, Hadejia, Nigeria \\ Email: ${ }^{\star}$ drbaba01@gmail.com
}

How to cite this paper: Baba, M.M., Talle, M.A., Buba, F. and Fagge, K.M. (2018) Left Atrial Myxoma in a Woman with Postpartum Heart Failure: The Culprit or an Incidental Bystander. Case Reports in Clinical Medicine, 7, 63-69.

https://doi.org/10.4236/crcm.2018.71006

Received: November 16, 2017

Accepted: January 15, 2018

Published: January 18, 2018

Copyright $\odot 2018$ by authors and Scientific Research Publishing Inc. This work is licensed under the Creative Commons Attribution International License (CC BY 4.0).

http://creativecommons.org/licenses/by/4.0/

\begin{abstract}
Myxoma is a benign and the most frequent tumor of the heart, accounting for approximately $30 \%$ of all primary cardiac tumors. Seventy five percent of atrial myxomas are in the left atrium. We present a case of a 20 -year-old house wife presenting with biventricular heart failure and chest infection five months after her last child birth. Transthoracic echocardiography showed a mobile left atrial echogenic mass measuring $4.6 \times 4.0 \mathrm{~cm}$ attached to the interatrial septum. Left ventricular systolic function was mildly reduced (EF 48\%) with mitral and tricuspid incompetence. A diagnosis of left atrial myxoma with biventricular heart failure with chest infection was made. She improved on antibiotics and treatment of heart failure, and referred to Aminu Kano Teaching Hospital for further management.
\end{abstract}

\section{Keywords}

Myxoma, Left Atrium, Postpartum Heart Failure

\section{Introduction}

Myxoma is a benign and the most frequent tumor of the heart, accounting for approximately $30 \%$ of all primary cardiac tumors. Seventy five percent of atrial myxomas are in the left atrium, attached to the margin of the fossa ovalis [1], with fever in other locations [2]. Myxomas can be quite large, occupying most of the left atrium resulting in obstruction to left ventricular filling, while prolapse of a tumor through the mitral valve may result in the destruction of the annulus or valve leaflets causing mitral valve regurgitation [3]. It occurs sporadically in 
all age groups, mostly between the third and sixth decades, and women are more commonly affected than men [4] [5]. Myxomas are slowly growing and usually remain asymptomatic and incidentally discovered in about $20 \%$ of cases [6].

Clinical presentation is categorized into four general manifestations as systemic, embolic, cardiac manifestations and phenomena secondary to metastatic diseases. Symptoms range from non-specific constitutional to sudden cardiac death [7]. Typically, patients show symptoms of left-sided heart failure (e.g. dyspnea, orthopnea, or fatigue) or syncope. About $30 \%-40 \%$ of individuals with cardiac myxomas experience embolic phenomena, occurring commonly with friable myxomas [8]. Sites of embolization include the central nervous system, kidneys, extremities, and coronary arteries. Nonspecific constitutional symptoms such as fever, arthralgia, myalgia, and weight loss are more common in women than men, and in those with right-sided myxoma [9] [10].

Elevated erythrocyte sedimentation rate, anemia, leukocytosis, thrombocytopenia, and elevated gamma globulins have been reported [11]. The diagnosis of left atrial myxoma can be established by demonstrating a characteristic echo producing mass in the left atrium using two-dimensional (2D) echocardiography [12]. Transthoracic echocardiography is approximately $90 \%$ sensitive in detection of left atrial myxoma [13] and the sensitivity of trans-esophageal echocardiogram approaches almost 100\% [14].

Ethical Matter: A verbal consent was obtained from both the patient and the husband before this case report was produced.

Objectives: Myxoma is a rare tumour occurring in an economically challenge patient during postpartum period posing a diagnostic dilemma in a resource poor setting.

\section{Case Presentation}

We present a case of a 20-year-old house wife presented five months after her last child birth with a two-week history of shortness of breath, pleuritic chest pain, fever and cough with hemoptysis. This was followed a week later by paroxysmal nocturnal dyspnea, orthopnea, and facial and pedal swelling. The last pregnancy and delivery were uneventful, and she did not suffer symptomatic heart failure in the past. Physical examination revealed an acutely ill-looking young lady with axillary temperature of $37^{\circ} \mathrm{C}$, a respiratory rate of 30 cycles per minute and bilateral pitting pedal edema. The pulse was of small volume but regular at 120 beats per minute, and the blood pressure was 100/70 mmHg. The jugular venous pressure was elevated. The point of maximum impulse was not displaced and was of normal character. The first heart sound had increased intensity and there was a third heart sound. She also had features of pulmonary hypertension and mitral and tricuspid insufficiency. There was no diastolic murmur. The breath sound was bronchial over the left axillary area with crackles. The liver was palpable $4 \mathrm{~cm}$ below the right costal margin, and was soft, smooth and tender with a span of $14 \mathrm{~cm}$. Spleen was not palpable and kidneys 
were not ballotable. Ascites was demonstrable by shifting dullness. Other systems were essentially normal. An initial assessment of congestive cardiac failure secondary to peripartum cardiomyopathy (PPCM) and chest infection was made. Complete blood count was normal. She had a PCV of $35 \%$ with target cells. Blood urea was 7 $\mathrm{mmol} / \mathrm{L}$ but creatinine and other electrolytes were within normal limits. Chest X-ray showed cardiomegaly with consolidation over the left lower zone (Figure 1). Electrocardiography (ECG) showed sinus tachycardia with right axis deviation, qR complex in V1 with large $\mathrm{R}$ wave and the S3Q3T3 pattern (Figure 2). Transthoracic

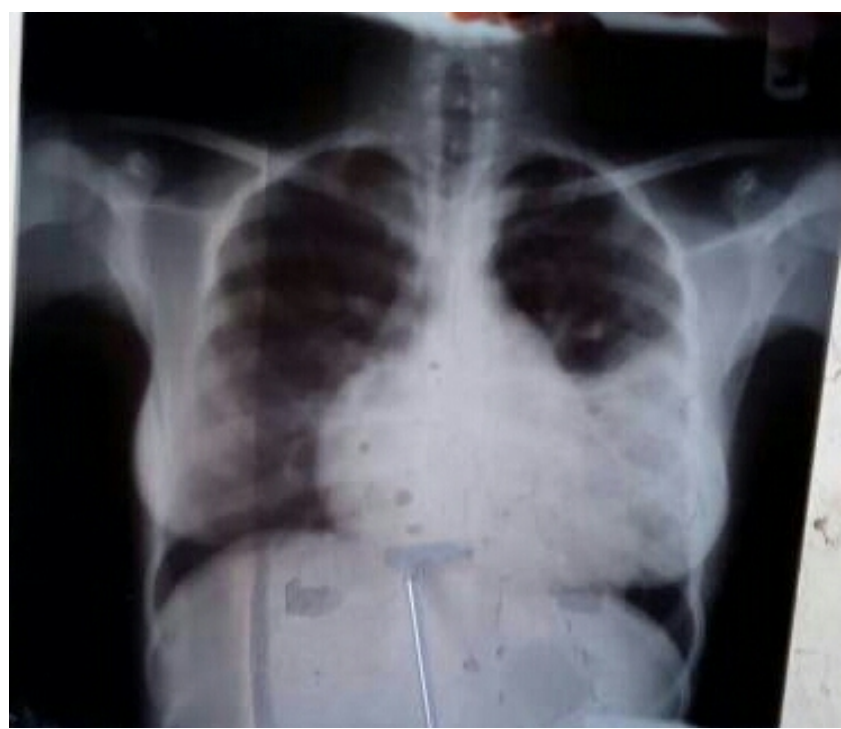

Figure 1. Chest X-ray showing cardiomegaly with left middle zone consolidation. NB-The metal on the film is an artefact.

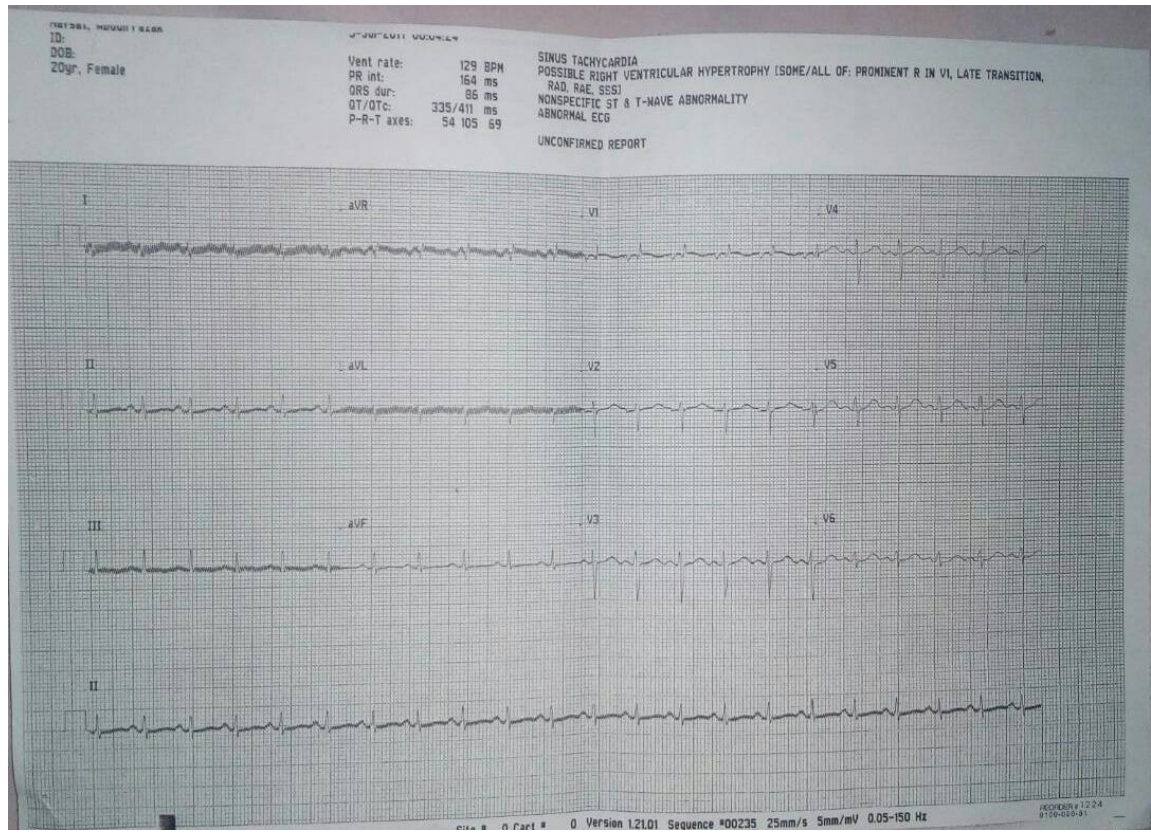

Figure 2. ECG showing sinus tachycardia. NB. Figure 2 is the only available ECG of the patient, because of the thermo sensitivity nature of the paper it has started fading. 
echocardiography showed a mobile left atrial mass measuring $4.6 \times 4.0 \mathrm{~cm}$ attached to the interatrial septum (Figure 3 ). The left ventricular internal diameter was normal $(4.8 \mathrm{~cm})$ with an ejection fraction of $48 \%$ and fractional shortening of $28 \%$. There was mitral and tricuspid regurgitation but there was no evidence of rheumatic valvular heart disease.

A diagnosis of biventricular heart failure with left atrial myxoma and chest infection was made. Patient was stabilized with conventional anti-cardiac failure regiment that includes: Digoxin, Spironolactone, Carvedilol, Furosemide and Lisinopril. She was also placed on low dose warfarin to prevent the formation of intracardiac thrombus. Ceftriaxone and Azithromycin were used for the chest infection. Following the improvement in her clinical condition and resolution of the chest infection, she was referred to Aminu Kano University Teaching Hospital for further management. Patient is unable to under the tumour resection surgery due to limited facility at the referred hospital hence she was further referred to South Africa. However, due to financial constraint, she is yet to be operated though currently out of heart failure on conservative management with Carvedilol, Spironolactone, Lisinopril and furosemide. The patient is not an enrollee of the Nigerian National Health Insurance Scheme. The scheme as well did not cover such procedure, hence posing a serious threat to her life.

\section{Discussions}

Our patient presented in her twenties with symptomatic heart failure five months postpartum, a time frame suggesting peripartum cardiomyopathy. Given the high rate of PPCM among our population in the northern Nigeria [15], the attending physician's initial clinical diagnosis was appropriate for the

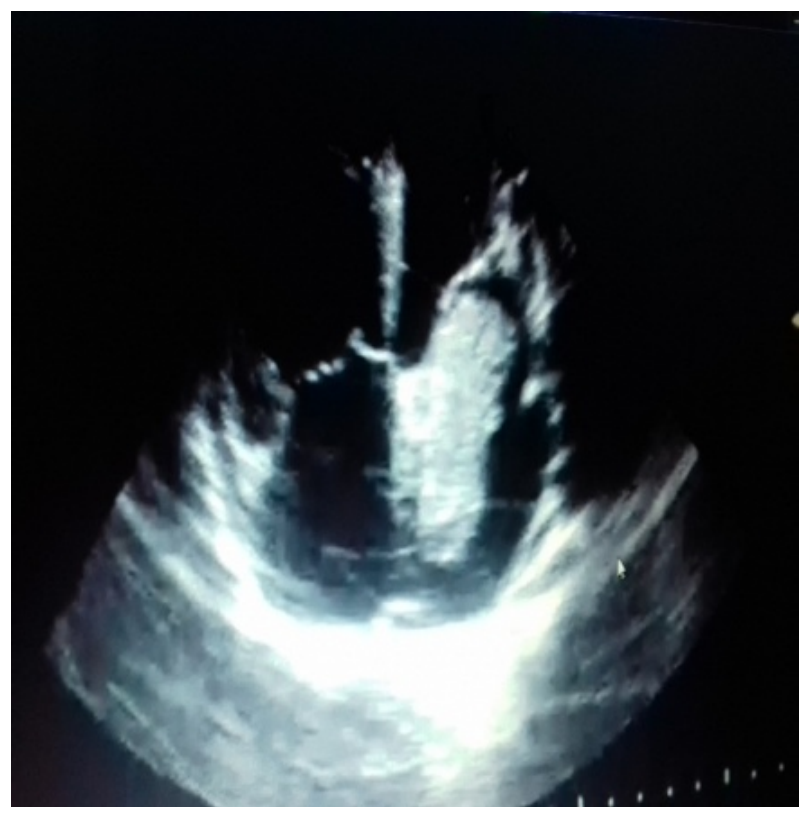

Figure 3. Apical four chamber view showing left atrial myxoma attached to the interatrial septum. 
circumstances, particularly where echocardiography was not readily available. The additional findings of chest infection, a common cause of breathlessness, suggested this to be the trigger of symptomatic heart failure in what might have been a subtle form previously unrecognized cardiac disorder, especially PPCM. Interestingly, the diagnosis of PPCM in our patient remains probable since the left ventricle (though dimension was not indexed to body surface area) was not dilated and the ejection fraction of $48 \%$ was above the threshold of $<45 \%$ required [16]. However, since patients with less profound forms of PPCM could achieve recovery of function and structure, the echo may be reflecting recovery from PPCM developed earlier, with the recent pneumonic process precipitating symptomatic heart failure.

The chest $\mathrm{x}$-ray revealed extensive involvement of the left hemithorax by a pneumonic process, which was confirmed by sputum culture. Pneumonia has been implicated in the etiology of difficulty in breathing especially during the early postpartum period. Other common etiologies of breathlessness in the postpartum period such as pulmonary thromboembolism (PTE), idiopathic dilated cardiomyopathy, unrecognized congenital heart disease and rheumatic heart disease are important differential diagnosis. Pulmonary embolism is commoner in the immediate postpartum period and that PPCM is associated with higher rates of thromboembolism than other forms of cardiomyopathy [17]. However, PTE remains important consideration given that our patient reported hemoptysis with pleuritic chest pain, and the ECG showed sinus tachycardia, the S1Q3T3 pattern, dominant $\mathrm{R}$ wave in $\mathrm{V} 1$ and right axis deviation. D-dimer, CT of the chest or V/Q scan was not done due to non-availability.

Our patient had fever and systolic murmur suggestive of mitral incompetence, warranting a diagnosis of probable infective endocarditis. Fever and other constitutional symptoms resulting from circulating cytokines could occur in both infection and tumors [9]. The findings of left atrial mass consistent with atrial myxoma along with distortion of the mitral valve apparatus, and the absence of discernable vegetation made endocarditis a secondary consideration. Understandably, transesophageal echocardiography was required to further evaluate for endocarditis, but not done due to unavailability. It is worthy of note that the mitral valve could be permanently damaged from repeated collision with the myxoma (wrecking-ball effect), resulting in the regurgitation observed in our patient. The rarity of cardiac myxoma in individuals younger than 30 years coupled with its protean manifestations and mimicry of cardiac symptoms favored the presumptive diagnosis of peripartum cardiomyopathy.

Our patient had significant improvement following treatment of chest infection with antibiotics and standard treatment of PPCM, suggesting that her symptoms might have been mainly driven by chest infection and heart failure rather than myxoma. However, she presented with symptoms that could result from each of the three considerations occurring in isolation. The protean manifestation of atrial myxoma with asymptomatic phase interspersed with con- 
stellation of cardiorespiratory symptoms will argue against myxoma being an innocent by-stander in our patient.

Myxoma is a sporadically occurring cardiac tumour affecting all groups, but commonly encountered in the third to sixth decades, with female preponderance [4]. The presentation is quite protean, ranging from asymptomatic, non-specific constitutional symptoms to various cardiovascular manifestations including embolic phenomenon. Cardiac myxoma in pregnancy or postpartum is rare; literature review published in 2015 reported only 51 cases from 44 publications [18], the female to male preponderance and similarity in symptomatology with cardiovascular dysfunction makes it an important differential diagnosis of postpartum breathlessness and heart failure.

The overall management of this patient highlights the prevailing difficulties associated with patient evaluation and treatment in our various centres. With the lack of readily available cardiothoracic surgical services, the sun cannot by any means be prevented from setting on virtually all the myxomas encountered in our practice.

\section{References}

[1] Reynen, K. (1995) Cardiac Myxoma. The New England Journal of Medicine, 14, 1610-1617. https://doi.org/10.1056/NEJM199512143332407

[2] Burke, A. and Virmani, R. (1996) Tumors of the Heart and the Great Vessels. In: Rosai, J., Ed., Atlas of Tumor Pathology, 3rd Edition, Fascicle 16, Armed Forces Institute of Pathology, Washington DC, 231.

[3] Bass, N.M. and Sherratt, G.P. (1973) Left Atrial Myxoma Diagnosed by Echocardiography, with Observations on Tumor Movement. British Heart Journal, 35, 1332-1335. https://doi.org/10.1136/hrt.35.12.1332

[4] Ramachandran Muthiah. (2016) Left Atrial Myxoma-A Case Report. Case Reports in Clinical Medicine, 5, 6-10. http://www.scirp.org/journal/crcm

[5] Zheng, J.J., Geng, X.G., Wang, H.C., Yan, Y. and Wang, H.Y. (2013) Clinical and Histopathological Analysis of 66 Cases with Cardiac Myxoma. Asian Pacific Journal of Cancer Prevention, 14, 1743-1746. https://doi.org/10.7314/APJCP.2013.14.3.1743

[6] Oliveira, R., Branco, L., Galrinho, A., Abreu, A., Abreu, J., et al. (2010) Cardiac Myxoma: A 13-Year Experience in Echocardiographic Diagnosis. Revista Portuguesa de Cardiologia, 29, 1087-1100.

[7] Rios, R.E., Burmeister, D.B. and Bean, E.W. (2016) Complications of Atrial Myxoma. American Journal of Emergency Medicine, 34, 2465.e1-2465.e2. https://doi.org/10.1016/j.ajem.2016.05.079

[8] Larsson, S., Lepore, V. and Kennergren, C. (1989) Atrial Myxomas: Results of 25 Years Experience and Review of the Literature. Surgery, 105, 695-698.

[9] Pinede, L., Duhaut, P. and Loire, R. (2001) Clinical Presentation of Left Atrial Cardiac Myxoma. A Series of 112 Consecutive Cases. Medicine (Baltimore), 80, 159-172. https://doi.org/10.1097/00005792-200105000-00002

[10] Thyagarajan, B., Kumar, M.P., Patel, S. and Agrawal, A. (2017) Extracardiac Manifestations of Atrial Myxomas. Journal of the Saudi Heart Association, 29, 37-43. https://doi.org/10.1016/j.jsha.2016.07.003

[11] Jelic, J., Milicić, D., Alfirević, I., et al. (1996) Cardiac Myxoma: Diagnostic Ap- 
proach, Surgical Treatment and Follow-Up. A Twenty Years Experience. The Journal of Cardiovascular Surgery ( Torino), 37, 113-117.

[12] Finogan, R.E. and Harrison, D.C. (1970) Diagnosis of Left Atrial Myxoma by Echocardiography. The New England Journal of Medicine, 282, 1022-1023. https://doi.org/10.1056/NEJM197004302821808

[13] Herbst, M., Wattjes, M.P., Urbach, H., et al. (2005) Cerebral Embolism from Left Atrial Myxoma Leading to Cerebral and Retinal Aneurysms: A Case Report. American Journal of Neuroradiology, 26, 666-669.

[14] Sung, R.J., Ghahramani, A.R., Mallon, S.M., et al. (1975) Hemodynamic Features of Prolapsing and Non-Prolapsing Left Atrial Myxoma. Circulation, 51, 342-349. https://doi.org/10.1161/01.CIR.51.2.342

[15] Karaye, K.M., Sa'idu, H. and Habib, A.G. (2011) Peripartum and Other Cardiomyopathies in a Nigerian Adult Population. International Journal of Cardiology, 147, 342-343. https://doi.org/10.1016/j.ijcard.2011.01.004

[16] Sliwa, K., Hilfiker-Kleiner, D., Petrie, M.C., et al. (2010) Current State of Knowledge on Aetiology, Diagnosis, Management, and Therapy of Peripartum Cardiomyopathy: A Position Statement from the Heart Failure Association of the European Society of Cardiology Working Group on Peripartum Cardiomyopathy. European Journal of Heart Failure, 12, 767-778. https://doi.org/10.1093/eurjhf/hfq120

[17] Elkayam, U. (2011) Clinical Characteristics of Peripartum Cardiomyopathy in the United States: Diagnosis, Prognosis, and Management. Journal of the American College of Cardiology, 58, 659-670. https://doi.org/10.1016/j.jacc.2011.03.047

[18] Yuan, S.M. (2015) Cardiac Myxoma in Pregnancy: A Comprehensive Review. Brazilian Journal of Cardiovascular Surgery, 30, 386-394.

https://doi.org/10.5935/1678-9741.20150012 